\title{
DIÁSPORA, COMUNIDADE E LITERATURA
}

\section{Camila Mello*}

Resumo: Neste texto, interessa-me discutir de que forma a literatura pode ser um veículo pelo qual autores expressam os conflitos de individuos que se vêem isolados em comunidades fechadas, como é o caso dos guetos de migrantes na Inglaterra. Para tal, trago os exemplos dos romances Shame e The Satanic L érses, de Salman Rushdie, e The Unbelonging, de Joan Riley. Conto também com as idéias teóricas de Zygmunt Bauman, Stuart Hall e Robert Young.

Palavras-chave. Diáspora; Comunidade; Hibridismo.

Não é uma questão do que as tradições fazem de nós, mas aquilo que nós fazemos das nossas tradições.

(Da Diáspora, p. 44)

Eu acredito que devemos ser transformados; africanos, caribenhos, indianos, paquistaneses, chineses, somos diferentes do que seríamos se não tivéssemos cruzado o oceano. (The Satanic Verses, 414)'

Uma das coisas que mais recordo sobre minhas aulas de História é o episódio que contava a tomada da Grécia pelos romanos. Lembro-me do orgulho que sentia ao levar para a escola meus dois fascículos mais queridos da coleção Povos do Passado, de Joan Forman (traduzido pela Editora Melhoramentos, 1990); nesses dois fascículos - Os Romanor e Os Gregos - eu folheava a história sangrenta que contava, com termos ingênuos, as glórias do poder. As maravilhosas descobertas feitas pelos gregos me encantavam; mas o grande momento das minhas leituras repetidas era o que retratava a dominaçào deste povo pelos impiedosos romanos.

Naquela época, não percebia que as histórias contadas em todos os outros fascículos da coleçào - Os Astecas, Os Maias, Os Egípicios, entre outros -mostravam o mesmo processo que tanto me fascinava nos gregos e romanos: a colonizaçào. A dominaçào de um povo por outro tem sido evento recorrente

Bacharel em letras pela Universidade do listado do Ris de lanciro, mestranda em literaturas de l.ingua Inglesa na mesma instituiçào.

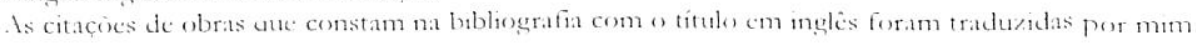


na nossa História, e cada vez mais se pensa sobre este processo, seja através de obras teóricas ou através da Arte.

Na segunda metade do século XX, vimos a independência de inúmeras colônias. A partir daí, fez-se necessário pensar e problematizar ainda mais questões relacionadas à cultura dos povos que encontraram seu país devassado pelo colonizador. Questòes relacionadas à identidade cultural e à reconstruçào de uma nação têm inspirado muitos estudiosos e artistas. Junto com o processo de descolonizaçào, vimos a migraçào densa de indivíduos de países periféricos para países centrais, seus antigos colonizadores. Este movimento denominado diáspora - causou enorme turbulência nos países centrais, já que a situação econômica, social e cultural de tais países sofreu modificaçòes com a vinda de milhòes de migrantes.

É claro que os problemas causados pela colonizaçào e pelo processo diaspórico não eram apresentados nos fascículos da coleção infantil sobre os povos do passado; hoje, porém, inspirada pelos estudos e manifestaçòes artísticas que discutem os dois processos, tais problemas interessam-me. Mais precisamente, é a vida destes migrantes no país colonizador que me instiga: como estes grupos migratórios vivem o encontro com uma nova cultura? Como lidam com o choque étnico? Como tentam manter suas "raízes"? Como são recebidos? Que saídas encontram para proteger suas tradiçòes? Todos estes detalhes me parecem muito interessantes, pois acredito que o encontro entre povos cria novas nações, com novas culturas, novas línguas, novas histórias - exatamente como ocorreu no Brasil.

Neste trabalho, pretendo mostrar de que forma obras ficcionais podem discutir algumas questões conflitantes vividas por estes grupos nos países centrais. Para fazê-lo, contarei com a romancista jamaicana Joan Riley e o indiano Salman Rushdie. Na obra de ambos os autores, a dificuldade de assimilação cultural, a saudade da terra-natal e a formação de guetos são alguns temas levantados. Mas, antes de falar de literatura, quero mostrar a dinâmica de formaçào e sobrevivência de grupos étnicos, sob a luz do estudo teórico intitulado Comunidade, do sociólogo polonês Zygmunt Bauman (2003).

\section{A busca por refúgio}

A criaçào de grupos minoritários, para Bauman, vem da formação do Estado-nação. Neste processo, dois planos destacam-se: o plano nacionalista, que busca assimilar as variedades e "dissolvê-las num padrào nacional", e o plano liberalista, que acredita na existência de uma essência nacional comum 
a todos (BAUMAN, 2003, p. 84-85). Ambos os planos negam a possibilidade de existência de uma sociedade autônoma dentro do Estado-naçào; todos devem assimilar a diferença do outro e diluir suas diferenças na igualdade nacional. Mas qual seria o padrào a ser seguido? A elite dominante o define. Tendo instituído o caminho a ser seguido por todos, este grupo dominante também tem o poder de dissociar um ou outro grupo do Estado-naçào: "a promessa de igualdade no final do tortuoso caminho da assimilaçào pode ser desfeita a qualquer momento sem que qualquer razào seja apresentada" (BAUMAN, 2003, p. 86).

Em outras palavras: todos podem ser diferentes, mas nem tanto, pois, se a diferença foge muito do padrào de assimilação, ela está descartada. Se pensarmos que estamos tratando de pessoas, e nào meramente de palavras em um texto, o esquema acima se mostra extremamente cruel. Diante disso, os indivíduos que têm sua assimilaçào negada unem-se, impulsionados pelo comunitarismo. Por mais que a formação da comunidade "fortaleza sitiada", nas palavras de Bauman traga proteçào, ela tem também um lado perverso: a sobrevivência da comunidade depende do fim da liberdade, pois para fazer parte deste tipo de grupo, "qualquer opçào que nào seja a lealdade incondicional à causa comum" é aniquilada (BAUMLAN, 2003, p. 88).

Bauman apresenta tais idéias sem especificar exatamente que comunidade ele tem em mente. No entanto, no final do capítulo sete, o autor discute a situação de minorias étnicas, principalmente aquelas que provêm de movimentos diaspóricos. Para Bauman, as minorias étnicas nunca são formadas por livre arbítrio, e sim por pressòes sociais: "os imigrantes nào têm escolha a nào ser tornar-se outra 'minoria étnica' no país de adoçào" (BALMLN, 2003. p. 94). O autor, longe de ser ingênuo em sua interpretaçào dos fatos, aponta que tal isolamento é de interesse político: poucos agentes governamentais trabalham em prol da aceitaçào do migrante, enquanto forças políticas atuam fortemente na promoçào do pensamento exclusivista, fomentando a construçào de barricadas cada vez mais intransponíveis. Essa verdade, denunciada por Bauman, é lastimável e fácil de ser comprovada: da mesma forma que os grupos étnicos na Inglaterra, por exemplo, sào mantidos sob controle em seus guetos, no Rio de Janeiro, os grupos mais empobrecidos são mantidos nas favelas através de açòes opressoras da polícia. Claro que os grupos na Inglaterra e as favelas no Rio apresentam histórias e realidades muito distintas, mas, a meu ver, o processo de manutençào de barricadas é muito semelhante nos dois casos. 
Bauman problematiza a política do multiculturalismo. Em teoria, esta política se destina ao reconhecimento das diferenças, mas na verdade este reconhecimento não é completo, pois nào é seguido da distribuiçào igualitária de direitos, salários, oportunidades, educaçào, entre outros itens. Ao mesmo tempo, o autor aponta que a falta de organizaçào e harmonia dentro dos grupos minoritários beneficia as classes dominantes: "a liberdade da elite depende da falta de ação comum dos 'nativos"' (BAUMAN, 2003, p. 96).

A comunidade nada mais é que um refúgio para os que procuram um ambiente seguro; no entanto, fazer parte de uma comunidade é viver no isolamento e na mesmice - "mesmice significa a ausência do Outro, especialmente um outro que teima em ser diferente" (BAUMAN, 2003, p. 104). Dessa forma, ao invés de protegidos, os migrantes tornam-se alienígenas ameaçadores para a sociedade local. Essa tensào chega ao seu clímax quando esta comunidade sente a necessidade de fechar-se, tanto socialmente, quanto fisicamente; seu território passa a ser delimitado. Esse tipo de comunidade é o gueto.

A questào da liberdade é crucial dentro do gueto: a saída e a entrada sào extremamente perigosas. Bauman utiliza o gueto étnico como os que existem na Inglaterra em prol da diáspora como um exemplo perfeito do agrupamento de indivíduos supostamente homogêneos por compartilharem a mesma etnia. Mas, como o autor nos lembra, a questào econômicué realmente o que define o habitante do gueto: seja qual for a procedência deste grupo de indivíduos, os pobres devem ser mantidos sempre isolados dos ricos (acredito, por exemplo, que um indiano com bom poder aquisitivo possa viver muito bem na Inglaterra). Bauman chega a afirmar que o gueto nào gera comunidade, pois "compartilhar o estigma e a humilhaçào pública nào faz irmàos os sofredores; antes alimenta o escárnio, o desprezo e o ódio. [...] A experiência do gueto dissolve a solidariedade e destrói a confiança mútua" (BAUMAN, 2003, p. 110). Particularmente, tenho algumas dúvidas sobre estas últimas afirmativas, mas tal discussào nào será desenvolvida neste trabalho.

A formaçào de guetos é sintoma dos conflitos entre migrantes e nativos, bem como uma soluçào buscada pelo migrante. Em Imaginary Homelands, Salman Rushdie apresenta outro subterfúgio fatalmente utilizado: a idealizaçào da terra-natal. "Iremos, enfim, criar ficçòes, nào cidades reais ou vilas, mas locais invisíveis, terras-natais imaginárias" (RUSHDIE, 1992, p. 10). Essa idealização gera um tipo de relaçào muito peculiar com a cultura do país deixado, ao mesmo tempo em que a relaçào do migrante com o país de 
adoção também é delicada. Assim, o migrante busca uma identic: de cultural, mas, paradoxalmente, encontra-se isolado.

Vale acrescentar aqui a importante contribuição de Stuart Hall para esta discussão. Em "New Ethnicities", Hall problematiza a questão da representação dos grupos que compõem um gueto. Segundo o autor, em um primeiro momento, o termo black foi utilizado na Inglaterra para designar a experiência de racismo e marginalização em comum entre diversos grupos, que apresentavam diferentes etnias, histórias e tradições. Este talvez seja um problema parecido com o que Bauman analisa através da política do multiculturalismo, na qual um termo guarda-chuva é utilizado em prol do apagamento das especificidades individuais. Em um segundo momento, felizmente, o autor identifica mudanças positivas nas representações de tais grupos (no caso de Hall, nos grupos afro-descendentes): “[...] os cenários de representação - subjetividade, identidade, política - [estão tomando um lugar] formativo, e não apenas expressivo, na constituição da vida social e política"; is to é, começa-se a perceber a cultura e a ideologia de grupos minoritários como constituintes de tais grupos, e não apenas reflexo deles (HALL, 1995, p. 224). Isto significa dizer que estamos começando a distinguir individualidades dentro de um grupo aparentemente homogêneo.

\section{O papel da literatura}

Todas essas questões tornaram-se muito evidentes na segunda metade do século XX, como já afirmei. Tradicionalmente, designamos os estudos referentes aos movimentos diaspóricos desta época de estudos pós-coloniais - estudos inspirados pela situação dos países e indivíduos que deixaram de ocupar o status de colônia e mantiveram uma relação conflitante com o colonizador através da diáspora. No entanto, vale colocar aqui que tal nomenclatura é bastante problematizada. Em "Shades of Empire in Colonial and Post-colonial Literatures", Theo D'Haen coloca os seguintes questionamentos sobre a literatura pós-colonial:

Quando começou a literatura colonial Inglesa? Deveríamos incluir as viagens de descoberta e sua literatura correspondente? [...] Ou talvez instituir o começo da literatura colonial Inglesa no estabelecimento de postos de troca, como a Índia, a partir do século XVIII? [...] Ou talvez devamos chamar tudo que foi escrito por ingleses sobre os países que pertenceram à Inglaterra de literatura 'colonial'? E tudo escrito na 
Inglaterra por individuos nào-ingleses sobre estes mesmos países de literatura 'pós-colonial', seja qual for a data? Parece que esta última opção é o consenso da critica contemporânea (D'HAEN, 1993, p. 11).

De fato, se analisarmos a escolha de termos pelo prisma histórico que $D^{\prime}$ Haen propõe, estaremos presos em uma cansativa discussào epistemológica. A meu ver, tal discussão tende a ser sempre dispensável. $\mathrm{O}$ próprio D’Haen, após perder-se em tantos termos e tantas datas, oferece a seguinte saída para o problema que propòe:

Tanto na literatura colonial como na pós-colonial, o confronto entre 'centro' e 'periferia' é o principal critério operacional. A diferença é se olhamos do centro para a margem ou da margem para o centro. No primeiro caso, lidamos com a literatura colonial; no segundo caso, a literatura pós-colonial (D’HAEN, 1993, p. 12).

Mais adiante, o autor aponta um fator que me parece ser primordial para a literatura pós-colonial: a crise de identidade, vivida por personagens que sofrem "uma inquietação, um desconforto, com sua tradição; [um personagem] prisioneiro de duas culturas às quais não pertence" (D'HAEN, 1993 , p. 13).

Esses conflitos nascem exatamente da condição do migrante no país de destino. É muitas vezes através da literatura que tais conflitos sào denunciados, e que a questão do migrante isolado em seu gueto vai receber atenção maior. Como exemplo disto, quero focalizar a chamada literatura migrante - literatura produzida por autores que passaram ou passam pela experiência da diáspora. A jamaicana Joan Riley e o indiano Salman Rushdie sào importantes representantes desse tipo de produçào literária. Em Imaginary. Homelands, Rushdie fala que o resultado da literatura produzida fora de seu país de origem é uma imagem fragmentada de sua cultura, sua história, e sua tradição. Mas, ao invés de ver isso como um aspecto negativo ou uma retrataçào distorcida de sua identidade cultural, Rushdie acredita que "o espelho quebrado talvez seja tão valioso quando o espelho supostamente inalterável” (RUSHDIE, 1992, p. 11). Esta idéia - que Rushdie espalha por seus romances - é, a meu ver, extremamente libertadora: entender que nossa identidade é totalmente plural e fragmentada é um grande passo em direção à aceitação do que julgamos ser diferente de nós; analogamente, percebendo que nossa cultura é altamente 
mutável, que na verdade ela nunca foi estática, podemos conseguir ver, no convívio com grupos minoritários, um fator de adiçào, e não de subtraçào. Isto significa destruir a noçào fixa de identidade cultural, como Hall a denuncia em Da Diáspora: "Possuir uma identidade cultural [...] é estar primordialmente em contato com um núcleo imutável e atemporal, ligando ao passado o futuro e o presente numa linha ininterrupta. Esse cordào umbilical é o que chamamos "tradição" (HALL, 2003, p. 29).

Em Shame, de Rushdie (1995), o narrador-autor discute a necessidade que o migrante tem de prender-se ao seu passado no país de origem: "Todo migrante deixa seu passado para trás, apesar de alguns tentarem o embrulhar em sacos ou caixas, [mas algo é sempre perdido]. O destino do migrante é ser desnudo de sua história" (1995, p. 63). A personagem que encarna este conceito é Bilquis Hyder, mulher que casa com o general Raza Hyder após ter sua casa perdida em chamas; toda sua história é apagada e ela passa a viver em outro lar, sob outra tradiçào familiar, como uma migrante.

O narrador-autor traz ainda outras discussòes sobre o comportamento do migrante no país de chegada: "A fim de explicar a ligaçào que temos com nossa terra-natal, pretendemos que somos árvores e falamos de raizes. Olhe embaixo dos seus pés. [...] Raízes, eu penso às vezes, sào mitos conservadores, destinados a nos manter fixos em nossos lugares" (RUSHDIE, 1995, p. 86). Este comentário um tanto irônico assemelha-se às idéias que Rushdie desenvolve em Imaginary Homelands: o apego às tradiçòes dificulta a convivência com o outro.

Ao mesmo tempo, negar o passado é um caminho perigoso. Em The Satanic Verses (1998), do mesmo autor, Saladin Chamcha - que divide o papel protagonista com Gibreel Farishta - sai da Índia porque nào se vê naturalmente parte daquela cultura. A Inglaterra é seu ideal. Chegando lá, Chamcha abandona sua origem para tornar-se um verdadeiro Englishman-inclusive com o sotaque apropriado. O resultado é a presença da terra-natal como um fantasma na vida de Chamcha, além da relaçào complicada com seu pai, que nào aceita a atitude do filho. Quando Chamcha retorna à Bombaim, vê-se impotente diante de seu antigo lar, que parece nào o reconhecer mais.

A questào do encontro entre culturas distintas está presente em todo The Satanic Verses através da idéia de metamorfose. Chamcha e Farishta sofrem modificaçōes contínuas: o romance começa com os dois personagens caindo de um avião que havia sofrido um ataque terrorista e, na queda, ambos transformam-se em anjos. A metamorfose dos personagens de Rushdie são representaçōes fantásticas do ser migrante como um ser híbrido. Sobre este 
assunto, em "Hybridity and Diaspora", Robert Young mostra que a cultura Inglesa, apesar de apresentar-se como fixa, sempre foi retratada na literatura como fluida é híbrida. O autor também aponta para uma crescente conscientização de que a hibridação cultural é um processo sadio e natural: "a heterogeneidade, o intercâmbio cultural e a diversidade tornaram-se a identidade autoconsciente da sociedade moderna" (YOUNG, 1995, p. 4). Em The Satanic Verses, o narrador adiciona: "Distinções baseadas na idéia do eu como sendo (idealmente) homogêneo, não-híbrido (puro) - uma noção altamente fantástica! - não pode, não deve, sobreviver" (RUSHDIE, 1998, p. 427).

Outra contribuição literária valiosa é The Unbelonging, primeiro romance de Joan Riley (1985). Ali, acompanhamos a infância e adolescência de Hyacinth, jamaicana levada à Inglaterra por seu pai contra sua vontade. O pai mostra-se altamente violento com a filha, em uma relação incestuosa de usurpação $e$ humilhação. Essa dinâmica entre Hyacinth e seu pai retrata a relação entre colonizador e colônia. O refúgio de Hyacinth é sonhar com seus amigos e sua avó que ficaram na Jamaica. Cada vez mais, ela apóia-se na esperança de um dia voltar para a terra-natal; mas o país que ela idealiza não é a Jamaica real que, na cronologia do romance, passava pelos conflitos da luta pela independência. Influenciada pelo racismo que seu pai cultivava ao explicar como os brancos odiavam os negros na Inglaterra, Hyacinth não acredita nas notícias que os jornais ingleses publicavam sobre a Jamaica em caos, uma Jamaica muito diferente daquela que ela queria lembrar: "[Hyacinth] achava difícil acreditar no que eles diziam: ela entendia porque os jornais ingleses mostravam estórias tão horrendas sobre a Jamaica - brancos nunca gostaram de jamaicanos" (RILEY, 1985, p. 110). Na faculdade, sua amiga Perlene - uma Jamaicana altamente politizada tentava advertir Hyacinth sobre a realidade de sua terra-natal - "Sai da sua bolha e vê a realidade, Hyacinth" - mas seus esforços eram inúteis; nos termos de Rushdie, Hyacinth apegou-se à sua imaginary homeland (RILEY, 1985, p. 111).

A protagonista de The Unbelonging volta à Jamaica. Chegando lá, encontra seu bairro altamente destruído pela miséria; sua avó está doente e velha; uma de suas amigas a recebe com hostilidade pelos anos que Hyacinth passou fora da Jamaica sem dar notícias. O país dos sonhos de Hyacinth desmorona; "este não era o lugar do qual ela lembrava" (RILEY, 1985, p. 137). Desta forma, como Maria Conceição Monteiro resume em "Corpos colonizados na fábula gótica de The Unbelonging",

Riley problematiza aspectos que afetam a vida de muitos negros que vivem em sociedades governadas por brancos, como, por exemplo, a dificuldade quanto à 
identificação cultural, a rejeição sexual, a interiorização de julgamentos racistas, bem como a normalizaçào das injustiças perpetradas pelos sistemas educacional, social, legal e político. Como conseqüência desses fatores, o romance é um estudo sobre o medo, a culpa e a violência (MONTEIRO, 2005, p. 122).

Os dois processos diaspóricos dos quais Rushdie e Riley participaram são distintos, mas ambos os autores incluem em suas obras os conflitos que a migraçào para a Inglaterra criou e, mais que isso, os problemas pelos quais o migrante passa, ao se ver diante de uma nova cultura, hostil à integração de estrangeiros. A literatura, portanto, pode levantar discussòes importantes sobre a vida em gueto dos migrantes - nos casos de Rushdie e Riley, na Inglaterra e problematizar a mentalidade de gueto. Mais do que isso, a literatura vem colocando o sujeito migrante, excêntrico e indesejado, na posiçào de sujeito; nas palavras de D'Haen, "Agora as literaturas pós-coloniais estào se escrevendo de volta no centro" (D’HAEN, 1993, p. 14).

\section{Possíveis soluções}

Segundo Bauman, o Estado mostra-se incapaz de oferecer proteçào e liberdade; assim sendo, os indivíduos, por si só, buscam um abrigo quase nuclear dentro da comunidade. Mas é na formaçào de grupos isolados que o diferente passa a ser um alienígena e uma ameaça. Essa questào vem sendo acentuada desde que os movimentos de diáspora vêm se intensificando; a migraçào traz desconforto, pois ela desestabiliza a noçào rígida de cultura. Através da literatura chamada pós-colonial e migrante, pode-se reverter essa situação e questionar a sobrevivência de tais grupos. Nos romances e trabalhos teóricos de Salman Rushdie, por exemplo, a própria formaçào de guetos é problematizada: "O maior e mais perigoso abismo seria a adoçào da mentalidade de gueto. Esquecer que este é um mundo além da comunidade à qual pertencemos, nos confinar dentro de estreitas fronteiras culturais, seria, acredito, [uma] forma de exilio interno" (RUSHDIE, 1992, p. 19). Nos romances do autor, "o ex-cêntrico, aquele que questiona e até destrói a tradiçào do centro, torna-se parte deste centro e de sua tradiçào" (D'HAEN, 1993, p. 16).

Algumas soluçòes para tais questòes sào apontadas nos trabalhos de Bauman e Rushdie. Para o primeiro, o diálogo entre culturas torna-se emergencial; esse diálogo só pode acontecer, no entanto, em um ambiente seguro (BALMAN, 2003, p. 128). Para Rushdie, o romance é a forma mais 
poderosa de negar a verdade "oficial"; através da ficçào, podemos questionar e até inverter o relacionamento entre indivíduos diferentes. Além disso, o autor clama que é importante entendermos que, no processo de migraçào há a tradução cultural e individual, e o resultado dessa traduçào é híbrido e positivo: "Normalmente supomos que algo sempre se perde na traduçào; eu clamo, obstinadamente, a noçào de que algo também pode ser ganho" (RUSHDIE, 1992, p. 17).

Eu havia dito, no começo deste trabalho, que é exatamente no processo de hibridaçào entre culturas que novas naçòes nascem $\cdots$ como ocorreu em meu país. Acredito que os autores que mencionei neste texto têm produzido obras fundamentais para que este processo seja reconhecido como necessário e positivo. Eles vêm tentando responder a seguinte pergunta que Stuart Hall propòe: "O que a experiência da diáspora causa aos nossos modelos de identidade cultural?” (HALL, 2003, p. 28). Ver a diáspora, o ser migrante e a vinda de novas culturas como algo negativo tem violência e gerado falta de harmonia. Acredito que precisamos, com urgência, entender os movimentos de diáspora iniciados na segunda metade do século XX, no que eles geram de mais enriquecedor: "uma subversão dos modelos culturais tradicionais orientados para a nação" (HALL, 2003, p. 36). Mas nada disso pode acontecer se a própria formação de comunidades é tào problemática, como Bauman sugere. Através das políticas de isolamento dessas comunidades, o caminho para a harmonia entre culturas fica cada vez mais obscuro; quando um grupo minoritário é pulverizado - nos termos de Bauman --, o processo de hibridaçao cultural é dificultado. O tradicionalismo e o conservadorismo geram estes problemas; um entendimento mais abrangente do que a cultura é facilitaria a soluçào desta situaçào. Fiquemos, entào, com a interessante noçào de cultura que Stuart Hall nos propòe:

A cultura não é apenas uma viagem de redescoberta, uma viagem de retorno. Não é uma 'arqueologia'. A cultura é uma produção. [...] Estamos sempre em processo de formação cultural. A cultura não é uma questão de ontologia, de ser, mas de se tornar (H.ALL, 2003, p. 44).

\section{REFERENNCIAS}

Bauman, Zygmunt. Comunidade: a busca por segurança no mundo atual. Rio de Janeiro: Jorge Zahar Ed., 2003. 
D' HAEN, Theo; BARFOOT, C.C. Shades of Empire in Colonial and Post-Colonial Literatures. Amsterdan: Rodopi, 1993.

HALL, Stuart. Da diáspora: identidades e mediações culturais. Belo Horizonte: Editora UFMG, 2003.

HALL, Stuart. New Ethnicities. In: ASHCROFT, Bill; GRIFFITHS, Gareth \& Tiffin, Helen. The Post-Colonials Studies Reader. London: Routledge, 1995.

MONTEIRO, Maria Conceição. Corpos colonizados na fábula gótica de The Unbelonging. In: LIMLA, Tereza Marques de Oliveira; MONTEIRO, Maria Conceiçào (Org.). Figurajöes do feminino nas manifestaçòes literárias. Rio de Janeiro: Caetés, 2005.

RILEY, Joan. The Unbelonging. London: The Women's Press, 1985.

RUSHDIE, Salman. Imaginary Homelands: Essays and Criticism 1981 - 1991. London: Penguin Books, 1992.

RUSHDIE, Salman. Shame. London: Vintage, 1995.

RUSHDIE, Salman. The Satanic V erses. Denmark: Vintage, 1998.

YOUNG, Robert. Colonial Desire: Hybridity in Theory, Culture and Race. London: Routledge, 1995. 